\title{
PRICE-SETTING IN UKRAINE: EVIDENCE FROM ONLINE PRICES
}

\author{
ANASTASIIA ANTONOVA ${ }^{\text {ab }}$ \\ ${ }^{a}$ National Bank of Ukraine, Kyiv, Ukraine \\ ${ }^{b}$ Aix-Marseille School of Economics, Marseille, France \\ E-mail: aantonova@kse.org.ua
}

Abstract

This study examines price duration and price-setting mechanisms in Ukraine using web-scraped prices. I found that the mean average duration of prices is about 2 months. Average price duration is lower for those products that are more exposed to temporary price changes (sales). Moreover, imported goods have a higher average price duration compared to domestic goods. In terms of the price-setting mechanism, the data supports timedependent price setting behavior over state-dependent. The evidence of time-dependent price setting is 1 ) the size of price change being positively related to the age of price; 2 ) many price changes of a size close to zero; and 3) the hazard function being non-increasing for the whole sample and tends to be flatter within relatively homogeneous groups of products.

JEL Codes C32, F42, F43, E32

Keywords sticky prices, price duration, online prices, price-setting scheme

\section{INTRODUCTION}

Price stickiness is an important structural parameter in many macroeconomic models. Knowing how often sellers reset their prices can help to achieve more precise calibration of a country's structural model, while understanding the price-setting mechanism can help to make the right modeling choices inside the micro-founded macroeconomic model.

Price stickiness strongly affects the dynamics of macroeconomic variables. When the degree of price stickiness is high, prices fail to adjust immediately in response to shocks. These lead to the non-neutrality of monetary policy, at least in the short run, among other things. For instance, when the monetary authority raises the nominal interest rate, the real interest rate increases because prices do not immediately react to keep the economy in its longrun equilibrium. Hence, the degree of price stickiness is an important characteristic of an economy for understanding how fast prices adjust and for modeling an economy's dynamic response to the actions of the monetary authority.

Broadly speaking, there are two types of price-setting models: time-dependent models and state-dependent models. In time-dependent models, firms reset their prices at exogenously set points in time. For instance, in a Calvotype price-setting model (Calvo, 1983) price change events are assigned randomly to firms. In state-dependent models, on the contrary, firms can choose when to reset their prices subject to menu costs (Golosov and Lucas, 2007). The Calvo-type price-setting model and menu-cost price-setting model are considered to be pure cases of time-dependent and state-dependent behavior, respectively. In the Calvo- type model, sellers reset their prices with some constant probability in each period. This means that some sellers are stuck with an old price for some time, even after observing change at the optimal price. In the menu-cost model, sellers can react to new economic developments every period, but are subject to paying fixed costs of price adjustment. Consequently, reacting to small changes in economic conditions is not optimal for them. As mentioned by Klenow and Kryvtsov (2008), the type of price-setting model has implications for monetary policy, as monetary shocks have a more slow and long-lasting effect in time-dependent models.

As more micro-data sources become available, it is possible to address directly the questions of price duration and price-setting behavior. Hence, many empirical studies are devoted to calculating price duration and understanding price-setting mechanisms using various sources of microlevel data on prices. For instance, Klenow and Malin (2010) use scanner data for the U.S. and euro area and find that the duration of prices is about half a year in the U.S. and about a year in euro area. Cavallo (2018) uses web-scraped data for the U.S. and some Latin American countries and finds that the duration of online prices is about 3 months in the U.S. and about 2 to 3 months in Latin countries. As discussed in Cavallo (2018), online and scanner data sources differ in their range of covered products, frequency of observations and availability of data for a wide range of countries. Gorodnichenko and Talavera (2017) find that in the U.S. and Canada, online prices are more flexible compared to offline prices.

The main advantage of online prices is their availability. In many countries, including Ukraine, where scanner data

\footnotetext{
${ }^{1}$ The opinions and conclusions in the paper are strictly those of the author and do not necessarily reflect the views of the National Bank of Ukraine or the Board members.

(c) National Bank of Ukraine, A. Antonova, 2019. This work is licensed under a Creative Commons Attribution-NonCommercial 4.0 International License. Avaliable at https://doi.org/10.26531/vnbu2019.248.01
} 
is not collected, online prices become the best available source of information on prices. That is why, starting from 2015, the National Bank of Ukraine collects online prices posted by the largest Ukrainian grocery stores.

The online dataset of the NBU covers the largest Ukrainian grocery stores in the five biggest cities: Kyiv, Kharkiv, Dnipro, Odesa, and Lviv. Faryna, Talavera, and Yukhymenko (2018) examined how well Ukraine's Consumer Price Index inflation can be captured by the NBU's online dataset. They found that the NBU's online prices dataset covers about $46 \%$ of Ukraine's Consumer Price Index basket and that CPI inflation estimated using online prices is consistent with the official estimates provided by the State Statistics Service of Ukraine. That is, the results obtained using this online dataset can be treated as an approximate description of price-setting behavior for the products included in the Ukrainian Consumer Price Index.

In this paper, I use the NBU's online dataset to look into the price duration and the price-setting behavior of Ukrainian grocery store retailers. This work is related to the research of Klenow and Malin (2010), who summarized most of the empirical findings of price-setting behavior in 10 stylized facts. I look at some of these stylized facts in the context of Ukrainian online data. In particular, the next questions are addressed: 1) the average duration of prices, 2) heterogeneity in price duration across goods, 3) distribution of the size of price changes, 4) the relationship between age of price and size of price change, and 5) the relationship between age of price and probability of price change ${ }^{2}$.

The average duration of online prices in Ukraine is about 2 months. However, the average price duration is extremely different for different groups of products. That is, for the group most exposed to the temporary price changes (sales), the mean average price duration is less than 2 months, while for the group least exposed to the temporary price changes, the mean average price duration is about 5.5 months. Moreover, import prices are more sticky than domestic prices.

Klenow and Kryvtsov (2008) divide U.S. inflation into an extensive margin (frequency of price changes) and intensive margin (size of price changes). The frequency of price change is related to state-dependent behavior, while the size of price changes is related to time-dependent behavior. Under the time-dependent price setting, the size of price change should be positively related to the age of price since shocks drive the current price further from the optimal price during the time when a firm is unable to reset its price. The probability of price change should not increase with the age of price if price-setting is time-dependent. Under the statedependent price-setting scheme, on the contrary, the size of price change is not related to the age of price, since the price change decision is based on how far the current price is from the optimum. Moreover, in menu-cost models, small price changes are not optimal since the firm bears the same size of menu costs regardless of the size of price change. Finally, in state-dependent models, the probability of price change should increase with the age of price since shocks drive the current price further from the optimal price as time passes, which raises the incentive to reset the price.

The NBU's online data support the time-dependent model of price-setting over the state-dependent model.
First, many price changes are close to zero. That is, small price changes are still optimal, which wouldn't be true under the menu-cost model of price-setting. Second, the size of price change is positively related to price duration. And finally, the hazard function is non-increasing and becomes more flat for relatively homogeneous product groups. These findings may suggest the time-dependent Calvo-type pricesetting model, with its different values of price stickiness for different products. Under a Calvo-type price-setting scheme and when price stickiness is the same for all products, the hazard rate is flat. But if there are several types of firms with different values of price stickiness, the resulting hazard rate decreases. Consequently, the decreasing hazard function may be the result of heterogeneity of prices under a timedependent, price-setting scheme.

The results outlined in this paper can be directly used in the structural model of the Ukrainian economy such as DSGE (dynamic stochastic general equilibrium) model. For instance, a Calvo-type price-setting scheme is a preferable choice for modeling the firm's behavior, while the value of the price-stickiness parameter for different groups of products can be calibrated from price duration values.

The rest of the paper is organized in the next order. Section 2 describes the data. Calculations of average price duration are presented in Section 3. Section 4 looks at the size of price changes. Section 5 contains a survival analysis and addresses the probability of price change. Section 6 offers a conclusion.

\section{DATA DESCRIPTION}

The NBU's online dataset consists of online prices posted by several of the largest grocery store retailers in Ukraine that were web-scraped during 168 weeks in 20152018. Observations of prices are presented with a weekly frequency. The dataset size is 168 weeks of observations for 314,789 products.

The original dataset is characterized by many price gaps - periods when the product price is not observed between two non-empty price observations. These gaps were filled by rolling forward the last non-empty price observation. According to research (Nakamura and Steinson, 2008), products for which the maximum price gap exceeds 5 months (20 weeks) were removed from the sample. Prices before the first price change for each product were removed since no information about their duration could be retrieved. Periods after the last observed price for each product were treated as censored observations. The dataset was further cleansed by removing those products that were present in the dataset less than $75 \%$ of the time. The final dataset consists of 40,943 products.

\section{AVERAGE PRICE DURATION}

The distribution of products by mean price duration is presented on Figure $1^{3}$. As one can see, most of the products in the sample have mean duration between 0 and 20 weeks. The descriptive statistics of the distribution of mean duration are presented in Table 1 (first column).

Products in the sample are extremely heterogeneous in terms of price change patterns. While some products are

\footnotetext{
${ }^{2}$ Unlike Klenow and Malin (2010), however, I don't address questions such as price synchronization over the business cycle and the link between price changes and wage changes due to a more narrow scope of the given research.

${ }^{3}$ The mean of price duration is calculated for each product based on price spells that ended in an observed price change event.
} 
strongly exposed to temporary price changes, others have more stable price patterns. Temporary price changes may include, for instance, sales and seasonal price adjustments. If the product is exposed to temporary price changes, many price increases will be followed by price decreases. On the contrary, if the product is not exposed to temporary price changes, its nominal price will move in one direction most of the time.

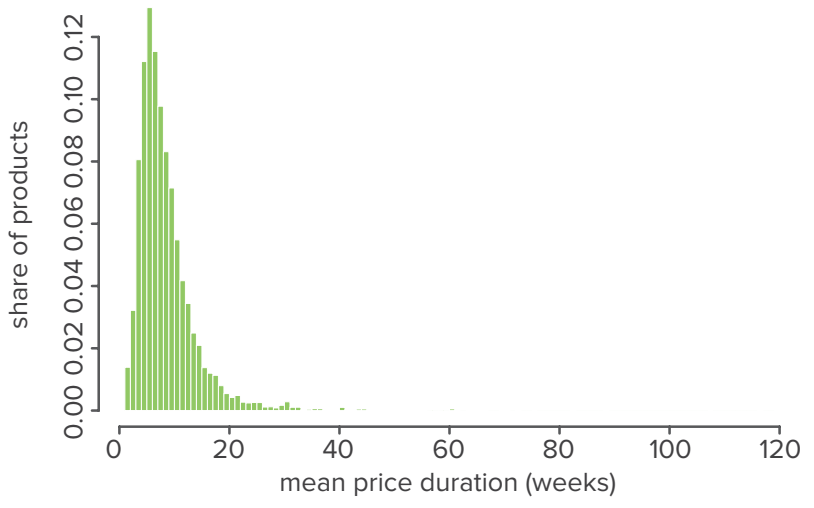

Figure 1. Distribution of Products by Mean Price Duration.

To group products by their degree of exposure to temporary price changes, I calculate the ratio of price decreases to overall price changes. For instance, if this ratio is around 0.5 , the number of price increases is roughly equal to the number of price decreases and, consequently, the product is exposed to the temporary price changes. On the other hand, if the ratio is close to 0 , the product price grows steadily without temporary fluctuations and, consequently, the product is not exposed to the temporary price changes.

The distribution of products by price decrease share is presented in Figure 2. Descriptive statistics of mean price duration for each group are given in Table 1.

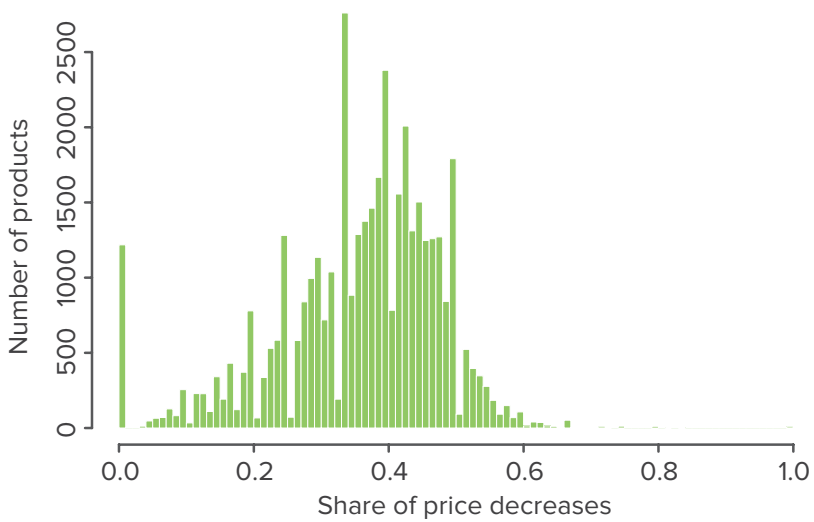

Figure 2. Number of Products by Share of Price Decreases in Overall Price Changes.

The overall mean of average price duration is approximately 8 weeks ( 2 months). However, for the group least exposed to temporary price changes, the average of the mean price duration is about 22 weeks (5.5 months). That is, products with the more stable price pattern on average have a higher price duration.

Next, I test whether there is a difference between imported and domestic products in terms of average
Table 1. Mean Price Duration (weeks) for Different Price Patterns.

\begin{tabular}{l|c|c|c|c}
\hline $\begin{array}{l}\text { Share of price } \\
\text { decreases }\end{array}$ & Mean & Median & Q1 & Q3 \\
\hline All & 8.58 & 7.18 & 5.11 & 10.31 \\
$\leq 0.05$ or $\geq 0.95$ & 22.00 & 17.69 & 12.08 & 29.62 \\
$\leq 0.15$ or $\geq 0.85$ & 16.08 & 13.10 & 8.83 & 18.20 \\
$\leq 0.25$ or $\geq 0.75$ & 13.17 & 11.00 & 7.75 & 15.38 \\
from 0.25 to 0.75 & 7.54 & 6.60 & 4.80 & 9.27 \\
\hline
\end{tabular}

duration. Table 2 presents the results of t-tests for the whole sample and various groups by share of price decreases $(\mathrm{HO}$ : the difference between means is zero).

Table 2. Difference between Imported and Domestic Goods. Results of t-test.

\begin{tabular}{l|c|c|c}
\hline $\begin{array}{l}\text { Share of price } \\
\text { decreases }\end{array}$ & $\begin{array}{c}\text { Mean } \\
\text { domestic }\end{array}$ & $\begin{array}{c}\text { Mean } \\
\text { imported }\end{array}$ & t-statistics \\
\hline All & 8.20 & 9.08 & 14.52 \\
$<0.05$ or $>0.95$ & 19.39 & 25.56 & 7.14 \\
$<0.15$ or $>0.85$ & 14.29 & 19.19 & 9.91 \\
$<0.25$ or $>0.75$ & 11.74 & 15.86 & 17.67 \\
from 0.25 to 0.75 & 7.26 & 7.90 & 13.28 \\
\hline
\end{tabular}

As one can see, imported goods have a higher mean of average price duration for all groups of products and the difference is statistically significant.

Overall, price duration depends on whether the product is exposed to temporary price changes. In the sub-samples with different degrees of exposure to a product's sales average, mean price duration varies from 7.5 to 22 weeks ${ }^{4}$. Imported goods have a higher price duration compared to domestic goods, and this difference is quite pronounced numerically. For instance, in the most stable price patterns group, the domestic goods have a price duration of about 19 weeks, while imported goods - about 25 weeks.

\section{SIZE OF PRICE CHANGE}

Under a time-dependent, price-setting scheme, the size of price change should be positively related to preceding price duration, while under state-dependent price setting, the size of price change should not depend on price duration. When the price setting is time-dependent, active price departs further away from its optimal level during the periods when the seller is unable to reset the price (see Klenow and Malin 2010). Consequently, when the time comes to reset the price, the size of the price change will be larger. Under state-dependent price setting, on the contrary, the seller can reset the price at any desired period and the size of price change is such that the benefits of price change exceed costs. That is, under the state-dependent price setting, the size of price change doesn't depend on the duration of the preceding price.

To look at the characteristics of each instance of price change, I construct the "survival dataset", where information about every price spell is recorded (price duration, whether the price was changed, size of price change, etc.). In this dataset, there are several price change events for most products, which makes it possible to use a fixed-effects 
Table 3. Descriptive Statistics of the Survival Dataset.

\begin{tabular}{l|c|c|c|c|c|c}
\hline Variable name & Min. & Q1 & Median & Mean & Q3 & Max. \\
\hline Price duration, weeks & 1.00 & 1.00 & 3.00 & 6.38 & 8.00 & 161.00 \\
Current price, UAH & 0.63 & 19.74 & 41.05 & 90.25 & 87.86 & $9,410.99$ \\
\hline Percentage price change, \% & -99.52 & -5.90 & 1.11 & 2.28 & 8.58 & 199.80 \\
CV & -2.89 & -2.89 & -2.89 & -2.89 & -2.89 & -2.89 \\
\hline
\end{tabular}

model to test the relationship between the size of the price change and price duration. Descriptive statistics of the survival dataset are given in Table 3 .

I drew estimates using the simple fixed effects model of the form:

$$
\begin{aligned}
& \mid \text { PercentageChange }_{t i} \mid=\text { FixedEffects }_{i}+\beta_{1}{ }^{*} \text { PriceDuration }_{t i}+ \\
& +\beta_{2}{ }^{*} I(\text { HighDurationti }=\text { TRUE }) * \text { PriceDuration }_{t i}{ }^{+} \\
& + \text {OtherCharacteristics }{ }_{t i}+\varepsilon_{t i} \text {, }
\end{aligned}
$$

where /PercentageChange ${ }_{t i}$ - absolute size of percentage price change ( $i$ - product index; $t$ - price change record index); FixedEffects ${ }_{i}$ - product unobserved fixed effects; PriceDuration $_{t i}$ - price duration;

I(HighDurationti=TRUE) - has value 1 if the age of price is higher than 7 weeks (with 7 weeks being roughly the mean price duration in the survival data-set); $\varepsilon_{t i}$ - residual. Hence, $\beta_{1}$ is the size of effect of duration on the size of price change for low-duration prices; $\beta_{1}+\beta_{2}$ is the size of effect of duration for high-duration prices.

Estimated results are presented in Table 4.
As apparent, there is a positive highly statistically significant relationship between price duration and size of price change. That is, for low-duration prices, a weak increase in duration is associated with a 0.7 percentage point-increase in size of price change. For high-duration prices, the association is much weaker but still positive and statistically significant. The positive relationship is stronger for imported goods.

The observed positive relationship between price duration and size of price change favors the time-dependent price setting scheme. For high-duration prices, however, the size observed relationship is numerically small - for one additional week of price duration, size of price change rises by 0.03 percentage points.

In Figure 3, one can see the distribution of size of price changes. Many price changes are close to zero, which can be interpreted as evidence against the state-dependent, menu-cost price setting.

Overall, since size of price change is positively related to the age of price, and since there are many small price changes, it can be said that the data favor the time-

\begin{tabular}{|c|c|c|c|c|}
\hline & \multicolumn{4}{|c|}{$\begin{array}{l}\text { Dependent variable: } \\
\text { abs(Price change) }\end{array}$} \\
\hline & (1) & $(2)$ & (3) IMP=1 & (4) $\mathrm{IMP}=0$ \\
\hline \multirow[t]{2}{*}{ Price duration } & $0.742^{* * *}$ & $0.720^{* * *}$ & $0.932^{* * *}$ & $0.549^{* * * *}$ \\
\hline & $(0.008)$ & $(0.008)$ & $(0.013)$ & (0.011) \\
\hline \multirow[t]{2}{*}{ High duration $X$ Price duration } & $-0.731^{* * *}$ & $-0.686^{* * *}$ & $-0.878^{* * *}$ & $-0.526^{* * *}$ \\
\hline & $(0.008)$ & $(0.008)$ & $(0.012)$ & $(0.010)$ \\
\hline \multirow[t]{2}{*}{ log(Current price) } & & $-12.246^{* * *}$ & $-17.575^{* * *}$ & $-10.120^{* * *}$ \\
\hline & & $(0.063)$ & $(0.122)$ & $(0.072)$ \\
\hline \multirow[t]{2}{*}{ Price increase } & & $-0.301^{* * *}$ & $-1.058^{* * *}$ & -0.021 \\
\hline & & $(0.024)$ & $(0.041)$ & $(0.030)$ \\
\hline Observations & 935,587 & 935,587 & 370,839 & 564,748 \\
\hline$R^{2}$ & 0.010 & 0.052 & 0.074 & 0.042 \\
\hline Adjusted $\mathrm{R}^{2}$ & -0.035 & 0.009 & 0.028 & 0.001 \\
\hline
\end{tabular}
dependent model of price setting.

Table 4. Size of Price Change and Price Duration. Fixed Effect Regression Estimates.

Note: ${ }^{*} p<0.1 ;{ }^{* *} p<0.05 ;{ }^{* * *} p<0.01$ 


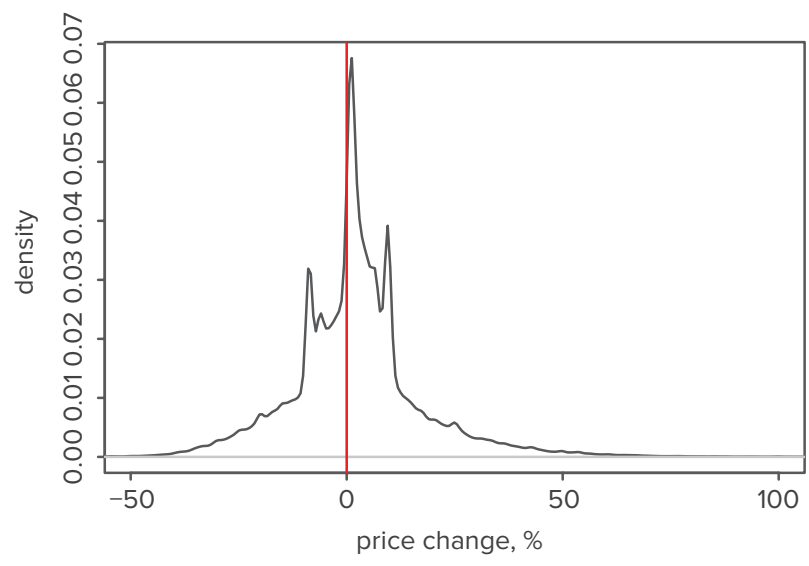

Figure 3. Distribution of Size of Price Changes.

\section{PROBABILITY OF PRICE CHANGE}

Under state-dependent price setting, the probability of resetting the price should be increasing with price duration since as price drifts further away from the optimum, the seller becomes more tempted to reset it. Under the timedependent price scheme, the conditional probability of price change should not depend on duration. For instance, under a Calvo-type price-setting scheme, the probability of resetting price each period (hazard rate) is constant.

To look at how the probability of price reset changes with duration, I construct a hazard function in which each value of price duration offers the conditional probability of resetting the price. I construct the non-parametric hazard function following Nelson (1972):
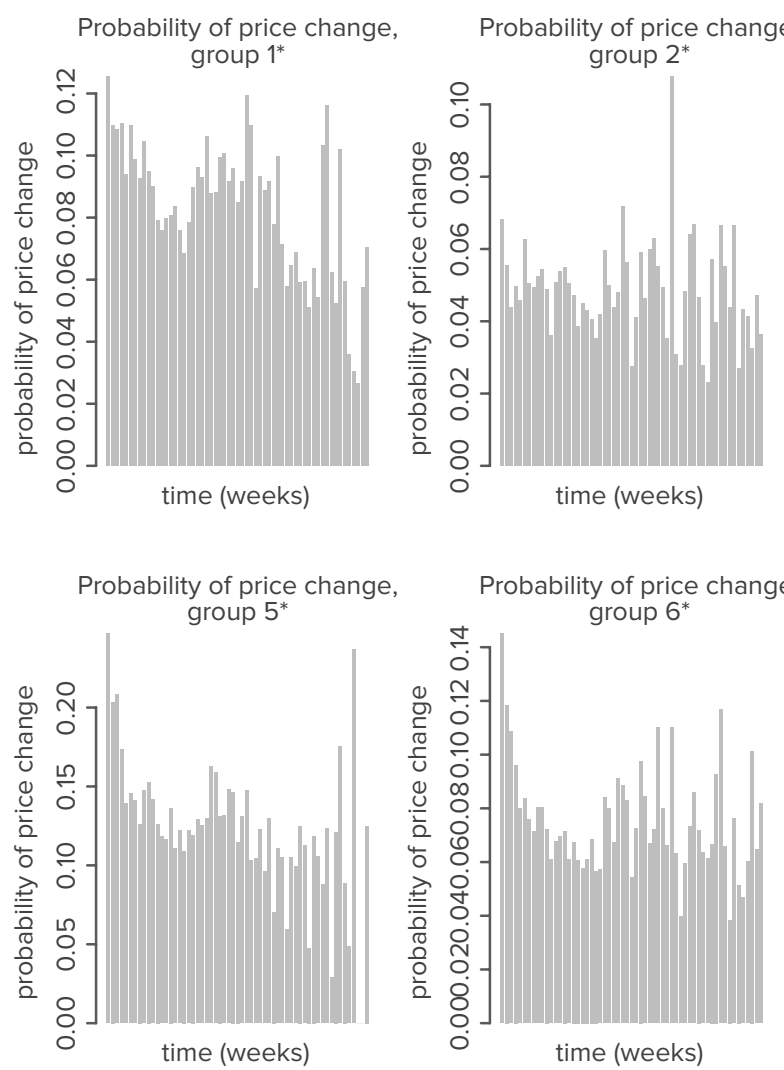

Figure 5. Distribution of Size of Price Changes by Product Groups. * - groups are described above.

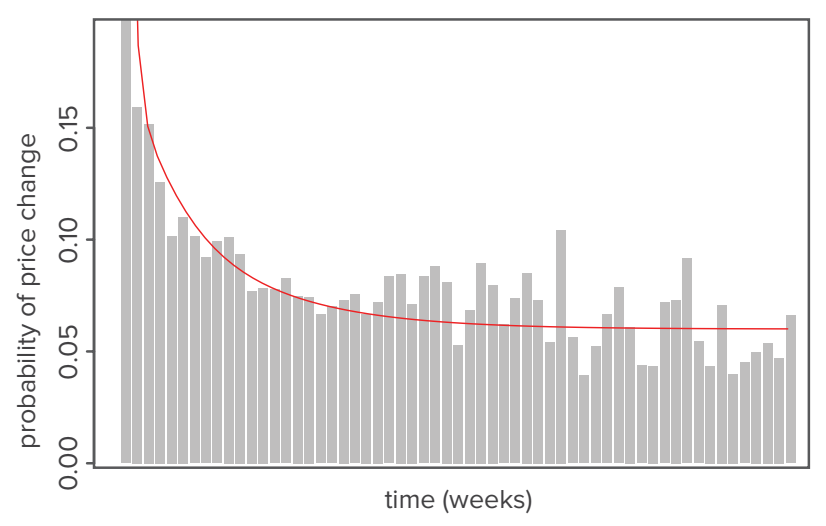

Figure 4. Price Duration and Probability of Price Change.

$$
h(j)=\frac{d_{j}}{n_{j}}
$$

where $h(j)$ - probability of price change for those prices with a still active price age $j ; d_{j}-$ number of price changes at price age $j ; n_{j}$ - number of prices that are at risk at price age $j$.

The probability of price change depending on duration is shown in Figure 4. As one can see, the hazard rate is nonincreasing, which may be viewed as evidence against statedependent price setting.

Under the Calvo-type price setting with constant price stickiness, the hazard rate is constant. But when prices are heterogeneous in terms of price stickiness (for different groups of products, for different periods, etc.), the hazard
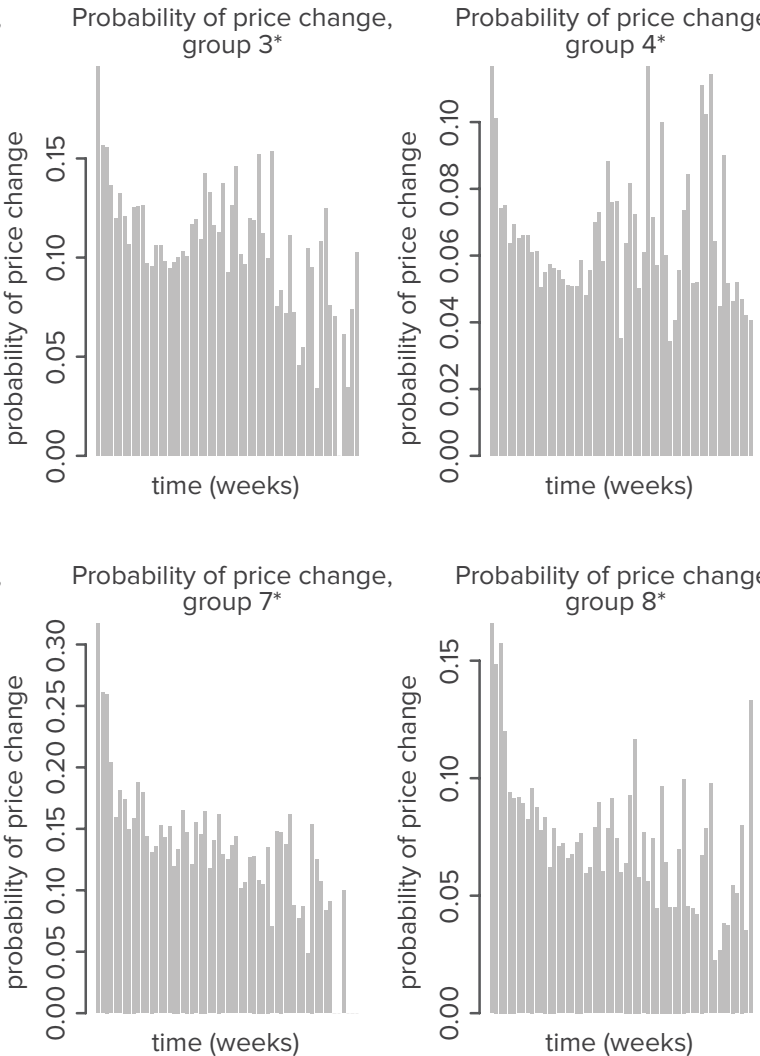

Probability of price change,

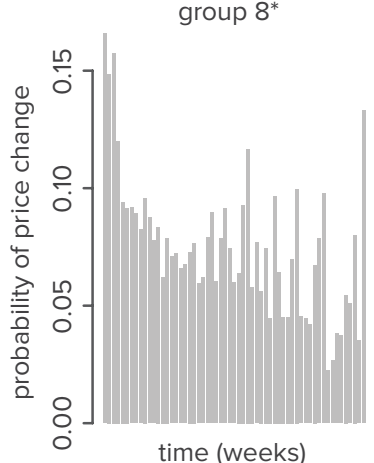


rate is decreasing even though each group of sellers follows a Calvo-type price-setting scheme (see Klenow and Kryvtsov, 2008). To illustrate this point, in Figure 4 (red line) the theoretical hazard function is built under the assumption that there are 4 equally sized groups of sellers with different rates of price stickiness (probabilities of price adjustment are $0.9,0.3,0.150 .06$ ). This shape of hazard function in the heterogeneous sample occurs due to survival bias, as the overall probability of price change drops as short-lived prices leave the sample.

To further explore whether the decreasing hazard is a result of heterogeneous products, I divide all products into 8 groups that are more homogeneous compared to the full sample. First, 4 groups are created - one for each quartile of the share of price decreases. Then, each of these 4 groups is divided into two subgroups - products above and below the median of average price duration in each group. The descriptive statistics used for dividing into groups are shown in Table 5.

Table 5. Descriptive Statistics of Product Groups.

\begin{tabular}{l|c|c|c}
\hline Quartile & $\begin{array}{c}\text { Share of price } \\
\text { decreases }\end{array}$ & $\begin{array}{c}\text { Group median } \\
\text { of average } \\
\text { duration }\end{array}$ & $\begin{array}{c}\text { Group names } \\
\text { (below/above } \\
\text { median) }\end{array}$ \\
\hline $25 \%$ & 0.294 & 10.000 & group1/group2 \\
\hline $50 \%$ & 0.375 & 7.842 & group3/group4 \\
$75 \%$ & 0.441 & 4.400 & group5/group6 \\
$100 \%$ & 1.000 & 5.276 & group7/group8 \\
\hline
\end{tabular}

Hazard rates for each group are plotted in Figure 5. As one can see, hazard rates are flatter when product groups are more homogeneous.
Overall, flatter hazard rates for more homogeneous groups of products - together with decreasing hazard for the whole sample - may be interpreted as evidence in favor of the Calvo-type, price-setting scheme with different degrees of price stickiness for different groups of prices.

\section{CONCLUSIONS}

Knowing price duration and understanding price-setting mechanisms is very useful when building and calibrating structural macroeconomic models. The availability of microlevel data makes it possible to examine directly the pricesetting behavior of retailers. This study addresses price duration and possible price-setting schemes using online prices posted by Ukrainian retailers.

First, the average price duration is about 2 months, but group estimates vary depending on the exposure of the product to temporary price changes (sales). Moreover, imported goods prices are stickier compared to domestic goods prices.

Second, the size of price change is positively related to the age of price, which together with the large number of small price changes presents evidence in favor of the timedependent, price-setting scheme.

Third, the probability of price change is non-increasing with age of price, which, again, can be looked at as evidence of a time-dependent, price-setting scheme with heterogeneous groups of products. In more homogeneous groups, hazard rates are more flat, which favors the Calvotype, price-setting mechanism with different degrees of price stickiness for different groups of prices.

\section{REFERENCES}

Calvo, G. A. (1983). Staggered prices in a utility-maximizing framework. Journal of Monetary Economics, 12(3), 383-398. https://doi.org/10.1016/0304-3932(83)90060-0

Cavallo, A. (2018). Scraped data and sticky prices. Review of Economics and Statistics, 100(1), 105-119. https://doi.org/10.1162/rest_a_00652

Faryna, O., Talavera, O., Yukhymenko T. (2018). What drives the differences between online and official price indexes? Visnyk of the National Bank of Ukraine, 243(1), 21-32. https://doi.org/10.26531/vnbu2018.243.021

Golosov, M., Lucas, Jr. R. E. (2007). Menu costs and Phillips curves. Journal of Political Economy, 115(2), 171-199. https://doi.org/10.1086/512625

Gorodnichenko, Y., Talavera, O. (2017). Price setting in online markets: Basic facts, international comparisons, and cross-border integration. American Economic Review, 107(1), 249-282. https://doi.org/10.1257/aer.20141127

Klenow, P.J., Malin, B. A. (2010). Microeconomic evidence on price-setting. Handbook of Monetary Economics, 3, 2010, 231-284. Elsevier. https://doi.org/10.1016/b978-0-444-53238$1.00006-5$

Klenow, P. J., Kryvtsov, O. (2008). State-dependent or time-dependent pricing: Does it matter for recent US inflation? The Quarterly Journal of Economics, 123(3), 863-904. https://doi.org/10.1162/qjec.2008.123.3.863

Nakamura, E., Steinsson, J. (2008). Five facts about prices: A reevaluation of menu cost models. The Quarterly Journal of Economics, 123(4), 1415-1464. https://doi.org/10.1162/qjec.2008.123.4.1415

Nelson, W. (1972). Theory and applications of hazard plotting for censored failure data. Technometrics, 14(4), 945-966. https://doi.org/10.1080/00401706.1972.10488991 


\section{APPENDIX \\ Price Stickiness and Price Duration}

Most of the New-Keynesian DSGE models make use of the Calvo-type price-setting scheme. A typical NK DSGE model is built in the discrete time with each time point corresponding to a quarter. Price stickiness is an important structural parameter of such a model. Price stickiness $\theta$ is the probability that a firm will not be able to reset it's price at a given quarter.

In reality, however, the firms exist in continuous time instead of discrete time. That is, if the firm is a Calvo-type price setter, the number of price-resetting events $X$ which occur at a given time interval $t$ is distributed via Poisson distribution:

$$
P(X=k ; t)=e^{-r t} \frac{(r t)^{k}}{k !}
$$

where $P(X=k ; t)$ - probability that the number of price-resetting events is equal to $k$ at the time interval $t ; r$ - the average number of events per unit of time.

From the data one can calculate the average duration of price, which is the average time between two price resetting events. When the number of events is distributed via Poisson, the time $T$ between the two consecutive events is distributed via exponential distribution:

$$
F(T \leq t)=1-F(T>t)=1-\left(P(X=0 ; t)=1-e^{-r t},\right.
$$

where $F(T \leq t)$ - probability that time between two events is less then $t$.

The mean of exponential distribution (the average time between the two events) is equal to $\frac{1}{r}$. This time is directly calculated from the data. Then the quarterly (12 weeks) price stickiness given the average price duration in weeks is:

$$
\theta=P(X=0 ; t=12 \text { weeks })=e^{-r t}=e^{-\frac{t}{1 / r}},
$$

The quarterly price stickiness calculated from the mean average duration for different groups of products is calculated in the Table below.

Table 6. Quarterly price stickiness for different groups of products

\begin{tabular}{l|c|c|c|c}
\hline Share of price decreases & $\begin{array}{c}\text { Duration } \\
\text { (domestic) }\end{array}$ & $\theta$ (domestic) & $\begin{array}{c}\text { Duration } \\
\text { (imported) }\end{array}$ & $\theta$ (imported) \\
\hline All & 8.201 & 0.231 & 9.081 & 0.266 \\
$<0.05$ or $>0.95$ & 19.385 & 0.538 & 25.556 & 0.625 \\
$<0.15$ or $>0.85$ & 14.290 & 0.432 & 19.192 & 0.535 \\
\hline$<0.25$ or $>0.75$ & 11.736 & 0.359 & 15.855 & 0.469 \\
\hline from 0.25 to 0.75 & 7.256 & 0.191 & 7.895 & 0.218 \\
\hline
\end{tabular}

